\title{
Effects of Kyusho Jitsu on Physical Activity-levels and Quality of Life in Breast Cancer Patients
}

\author{
MAXIMILIAN ALEXANDER STRUNK ${ }^{1}$, EVA M. ZOPF ${ }^{2}$, JULE STECK ${ }^{1}$, \\ STEFANIE HAMACHER ${ }^{3}$, MICHAEL HALLEK ${ }^{1}$ and FREERK T. BAUMANN ${ }^{1}$ \\ ${ }^{1}$ Department I of Internal Medicine, Center of Integrated Oncology Köln Bonn, \\ University Hospital of Cologne, Cologne, Germany; \\ ${ }^{2}$ Mary MacKillop Institute for Health Research, Australian Catholic University, Melbourne, Australia; \\ ${ }^{3}$ Institute of Medical Statistics and Computational Biology University Hospital of Cologne, Cologne, Germany
}

\begin{abstract}
Background/Aim: Breast cancer survivors often report a decrease in physical activity levels and quality of life. The aim of this study was to explore whether a "Kyusho Jitsu" martial arts intervention is feasible and can improve general well-being and physical activity levels in breast cancer survivors. Materials and Methods: Breast cancer survivors $(N=51)$ were randomly assigned to the intervention or control group. The intervention group participated in a 24-week Kyusho Jitsu intervention. Both groups were assessed at baseline, 3, and 6 months. Results: Analysis of original data showed several significant improvements in favor of the intervention group, but also some of the control group. Sensitivity analysis supports these findings. No adverse events were observed. Conclusion: To our knowledge this is the first study showing that a holistic Kyusho Jitsu martial arts intervention can be feasible and effective for breast cancer survivors.
\end{abstract}

Currently, breast cancer affects approximately $12 \%$ of all women (1) and is by far the most common female cancer (23\% of all cancers) (2). With a 5-year survival rate of almost $90 \%$ (3) there is an increased focus on enhancing survivorship care. Over the past few years, medical treatments have improved rapidly with a wide range of different therapy options available. However, there are numerous acute as well as chronic treatment-related side

This article is freely accessible online.

Correspondence to: Freerk T. Baumann, Department I of Internal Medicine, Center of Integrated Oncology Köln Bonn, University Hospital of Cologne, Kerpener Str. 62, Cologne, NRW 50937, Germany. E-mail: freerk.baumann@uk-koeln.de

Key Words: Breast neoplasm, exercise, martial arts, physical activity, quality of life, Kyusho Jitsu. effects. Patients experience physical (4), psychological (5) and psychosocial impairments. Impaired upper extremity range of motion, low physical activity level, lymphedema, fatigue, pain, depression and chemotherapy-induced peripheral neuropathy (CIPN) are well-documented (6-10), which negatively affect quality of life (11). In the past few years numerous studies have shown that exercise programs can significantly improve treatment-related side effects such as lymphedema and fatigue $(12,13)$. Different training protocols have been evaluated, however only few studies have investigated the influence of martial arts interventions in the prevention of mental disorders (14) or the rehabilitation of cancer (15), in particular breast cancer (16, 17). These studies found, that martial arts interventions are not only feasible and acceptable (15) but may also reduce stress, anxiety, and depression, and improve general psychosocial well-being (14). One study even found a significant reduction in one of the most common side-effects of breast cancer treatment: fatigue (16). To further explore the effects of martial arts interventions in breast cancer patients, this study was designed and conducted to to assess the feasibility of a "Kyusho Jitsu"-based intervention.

\section{Materials and Methods}

This feasibility study was a prospective, randomized-controlled twoarmed intervention trial. A total of 51 female breast cancer patients were randomly assigned to the intervention or the control group. The exercise intervention consisted of a 24-week holistic training program which was based on "Kyusho Jitsu" martial arts, "the art of vital points". The study was conducted under consideration of the "Declaration of Helsinki" (18). It was approved by the human research ethical committee of the German University of Sports Cologne and was registered in the German Clinical Trials Register (DRKS-ID: DRKS00011245).

The sample size for this pilot study was estimated based on infrastructural capacity and human resources. A maximum of 60 patients could have been included in the study. Participants were recruited via local newspaper advertisement between 16th of June 
Table I. Baseline characteristics of the intervention and control group.

\begin{tabular}{lccc}
\hline & Intervention $(\mathrm{n}=30)$ & Control $(\mathrm{n}=21)$ & $p$-Value \\
\hline Age (years) & $54.2 \pm 7.8(\mathrm{n}=30)$ & $51.5 \pm 8.4(\mathrm{n}=21)$ & 0.244 \\
Time since diagnosis (months) & $48.3 \pm 44.4(\mathrm{n}=29)$ & $39.8 \pm 34.5(\mathrm{n}=21)$ & 0.466 \\
Chemotherapy (\%) & $14(48 \% . \mathrm{n}=29)$ & $15(71 \% . \mathrm{n}=21)$ & 0.102 \\
Radiotherapy (\%) & $23(77 \% . \mathrm{n}=30)$ & $17(81 \% . \mathrm{n}=21)$ & 0.714 \\
Surgery (\%) & $29(100 \% . \mathrm{n}=29)$ & $21(100 \% \cdot \mathrm{n}=21)$ & $\mathrm{NA}$ \\
Hormone treatment $(\%)$ & $21(71 \% . \mathrm{n}=29)$ & $15(72 \% . \mathrm{n}=21)$ & 0.939 \\
Antibodies & $4(15 \%, \mathrm{n}=26)$ & $2(11 \% . \mathrm{n}=18)$ & 0.685 \\
\hline
\end{tabular}

2014 and 9th of September 2014. In order to take part in the study, participants had to be female breast cancer patients, aged 18 years or older, and within six months of completing medical treatment (excluding hormone treatment). All patients had to provide written consent before they were enrolled into the study. Patients were excluded from the study if they had a metastatic disease, underwent surgery or chemotherapy in the past 6 months, had a severe medical condition that could place the participant at unreasonable risk of injury or illness caused by the exercise program.

Patients in both groups were asked to complete a demographic and health history questionnaire. Additionally, we defined adverse events as any physical injury or harm that was caused by the intervention. Finally, feasibility was determined based on the dropout rate $(<30 \%)$ or reporting of adverse events (none). The primary aim of the study was to determine the feasibility of the "Kyusho Jitsu" martial arts intervention. The secondary outcomes included health-related quality of life and physical activity behaviour. All outcomes were assessed at baseline, after 12 weeks (T1) and after 24 weeks (T2).

Health-related quality of life was assessed using the EORTC (European Organization for Research and Treatment of Cancer) Quality-of-Life Questionnaire "QLQ-C30" and its breast cancer specific module "QLQ-BR 23“ (19). Physical activity levels were assessed using the 16-item GPAQ (Global Physical Activity Questionnaire) (20), which collects information on physical activity behavior in three different settings (activity at work, travel to and from places, recreational activities) as well as sedentary behavior. The reported activity levels were converted into metabolic equivalents (MET).

The exercise intervention involved a 24 -week holistic training program which was based on "Kyusho Jitsu" martial arts, "the art of vital points". Participants were asked to attend two exercise sessions per week for 90 minutes each. The training included several aspects of martial arts as well as self-defence, body related cognition, breathing exercise, meditation, stretching and physical strengthening. In addition, Kyusho Jitsu uses different techniques of Tai Chi and Qi Gong. The training was split up into two main parts, a warm-up phase and a martial arts phase. The intention of the 45-minute warm-up session was not only to improve physical fitness but also to ensure correct techniques and improve patients overall exercise expertise. The warm-up included coordination, mobilisation (upper body focus), strengthening and aerobic exercises. It also incorporated trust building exercises to promote psychological well-being and anxiety management. The second section was split up into three subparts: Kyusho Jitsu Training (20 minutes), Katha (continuous fight sequence for about 5 minutes) and meditation (15 minutes). The duration of the exercises varied between individuals. The third and last subpart of the second section involved a mediation ritual during which patients were able to relax and strengthen their vital points (based on the body "meridians" from the Chinese medicine). The training sessions took place at the German Sport University Cologne and were supervised by professional instructors. Patients in the control group received no Kyusho Jitsu intervention.

Ethics approval and consent to participate. Ethics Approval/ Approval of the Ethics Committee: Approved (leading) Ethics Committee, German University of Sports Cologne (Prof. Meinberg).

Statistical analysis. Patient characteristics were described using mean \pm standard deviation (SD) or median (interquartile range (IQR)) and count (percentage), as appropriate. Potential baseline differences between groups in age and time since diagnosis were investigated using separate independent $t$-tests. Differences in cancer treatments (surgery, chemotherapy, radiation, hormone treatment, antibody therapy) were analyzed using Chi-square test. Normal distribution of dependent variables was tested with the Kolmogorov-Smirnov test. The original data was analyzed using the Wilcoxon-Test (between Baseline and 3 months, between 3 months and 6 months, between 3 months and 6 months) with a significance level of $\alpha=5 \%$, two-sided. We used the Mann-Whitney $U$-test (deviation of 3 months and baseline, 6 months and baseline). Results are presented as mean $\pm \mathrm{SD}$, median (IQR or mean difference and $95 \%$ confidence interval (CI)), respectively, and absolute and relative frequencies. The analysis was done using SPSS Statistics 24 (IBM Corp., Armonk, NY, USA).

\section{Results}

A total of 60 patients were enrolled in the study. Nine women did not attend the first assessment session, leaving 51 patients in total: 30 patients in the intervention group and 21 patients in the control group. Both groups were comparable with regard to the most relevant clinical data at baseline (Table I). However, patients in the control group were slightly younger.

Overall, 19 women dropped-out of the study between baseline and the first follow-up assessment (3 months). Another two patients dropped out between the first and 
Table II. Original Data from the EORTC QLQ-C3O (mean \pm s.d.) in the intervention and the control group and the results of the INTRA group comparison (Wilcoxon-test).

\begin{tabular}{|c|c|c|c|c|c|c|c|}
\hline EORTC-QLQ-C30 parameters & Group & Baseline & 3 months & 6 months & $\begin{array}{c}p \text {-Value } \\
\text { (intragroup) } \\
\text { from baseline } \\
\text { to } 3 \text { months }\end{array}$ & $\begin{array}{c}p \text {-Value } \\
\text { (intragroup) } \\
\text { from } 3 \text { months } \\
\text { to } 6 \text { months }\end{array}$ & $\begin{array}{c}p \text {-Value } \\
\text { (intragroup) } \\
\text { from baseline } \\
\text { to } 6 \text { months }\end{array}$ \\
\hline \multirow[t]{2}{*}{ Global quality of life (Q:29.30) } & Intervention & $58.33 \pm 14.60$ & $68.75 \pm 13.44$ & $70.83 \pm 15.52$ & 0.06 & 0.43 & 0.01 \\
\hline & Control & $64.29 \pm 14.94$ & $67.42 \pm 16.01$ & $61.54 \pm 21.93$ & 0.86 & 0.52 & 0.82 \\
\hline \multirow[t]{2}{*}{ Physical functioning (Q:1-5) } & Intervention & $81.61 \pm 10.79$ & $82.50 \pm 10.29$ & $84.58 \pm 12.35$ & 0.53 & 0.20 & 0.72 \\
\hline & Control & $89.12 \pm 11.16$ & $89.09 \pm 13.42$ & $87.78 \pm 11.31$ & 0.07 & 0.10 & 0.20 \\
\hline \multirow[t]{2}{*}{ Role functioning (Q:6-7) } & Intervention & $62.07 \pm 25.93$ & $68.75 \pm 19.12$ & $71.88 \pm 21.70$ & 0.25 & 0.89 & 0.10 \\
\hline & Control & $73.81 \pm 29.14$ & $69.70 \pm 34.82$ & $70.51 \pm 28.18$ & 0.92 & 0.85 & 1.00 \\
\hline \multirow[t]{2}{*}{ Emotional functioning (Q:21-24) } & Intervention & $50.00 \pm 21.36$ & $52.78 \pm 19.07$ & $69.27 \pm 20.35$ & 0.65 & 0.01 & $<0.01$ \\
\hline & Control & $53.97 \pm 23.22$ & $54.55 \pm 29.90$ & $58.33 \pm 24.30$ & 0.13 & 0.37 & 0.08 \\
\hline \multirow[t]{2}{*}{ Cognitive functioning (Q:20.25) } & Intervention & $67.24 \pm 20.16$ & $68.89 \pm 21.70$ & $71.11 \pm 22.24$ & 0.48 & 0.43 & 0.61 \\
\hline & Control & $66.67 \pm 28.38$ & $66.67 \pm 31.62$ & $71.79 \pm 24.89$ & 0.80 & 0.08 & 0.18 \\
\hline \multirow[t]{2}{*}{ Social functioning (Q:26-27) } & Intervention & $60.92 \pm 22.39$ & $71.88 \pm 20.83$ & $77.78 \pm 19.59$ & 0.23 & 0.55 & 0.05 \\
\hline & Control & $61.11 \pm 33.47$ & $74.24 \pm 23.99$ & $73.08 \pm 32.30$ & 0.01 & 0.77 & 0.03 \\
\hline \multirow[t]{2}{*}{ Fatigue (Q:10.12.18) } & Intervention & $50.96 \pm 20.68$ & $42.36 \pm 24.42$ & $36.30 \pm 17.55$ & 0.04 & 0.08 & 0.01 \\
\hline & Control & $38.62 \pm 26.67$ & $36.36 \pm 22.82$ & $38.46 \pm 27.07$ & 0.67 & 0.76 & 0.78 \\
\hline \multirow[t]{2}{*}{ Nausea and vomiting (Q:14-15) } & Intervention & $8.62 \pm 20.23$ & $6.25 \pm 10.32$ & $3.13 \pm 9.07$ & 1.00 & 0.56 & 0.71 \\
\hline & Control & $5.56 \pm 10.97$ & $4.55 \pm 7.78$ & $7.69 \pm 11.00$ & 0.08 & 0.18 & 0.74 \\
\hline \multirow[t]{2}{*}{ Pain (Q:9.19) } & Intervention & $45.83 \pm 26.30$ & $29.17 \pm 27.55$ & $26.04 \pm 21.05$ & 0.01 & 0.93 & $<0.01$ \\
\hline & Control & $35.71 \pm 29.00$ & $25.76 \pm 21.56$ & $30.77 \pm 31.07$ & 0.26 & 0.67 & 0.28 \\
\hline \multirow[t]{2}{*}{ Dyspnea (Q:8) } & Intervention & $25.29 \pm 24.65$ & $22.92 \pm 20.07$ & $25.00 \pm 25.82$ & 0.32 & 1.00 & 0.26 \\
\hline & Control & $28.57 \pm 30.34$ & $12.12 \pm 22.47$ & $25.64 \pm 27.74$ & 0.21 & 0.26 & 0.41 \\
\hline \multirow[t]{2}{*}{ Insomnia (Q:11) } & Intervention & $47.13 \pm 36.21$ & $47.92 \pm 34.36$ & $50.00 \pm 34.43$ & 0.53 & 1.00 & 1.00 \\
\hline & Control & $46.03 \pm 32.45$ & $33.33 \pm 33.33$ & $46.15 \pm 34.80$ & 0.08 & 0.48 & 0.37 \\
\hline \multirow[t]{2}{*}{ Apetite loss (Q:13) } & Intervention & $8.05 \pm 19.22$ & $8.33 \pm 19.25$ & $2.08 \pm 8.33$ & 0.41 & 0.32 & 0.56 \\
\hline & Control & $9.52 \pm 21.46$ & $3.03 \pm 10.05$ & $15.38 \pm 25.88$ & 0.41 & 0.19 & 0.89 \\
\hline \multirow[t]{2}{*}{ Constipation (Q:16) } & Intervention & $10.71 \pm 22.32$ & $6.25 \pm 13.44$ & $4.17 \pm 11.39$ & 0.41 & 1.00 & 0.33 \\
\hline & Control & $3.17 \pm 10.03$ & $0.00 \pm 0.00$ & $8.33 \pm 15.08$ & 0.32 & 0.16 & 0.56 \\
\hline \multirow[t]{2}{*}{ Diarrhoea (Q:17) } & Intervention & $8.05 \pm 26.21$ & $14.58 \pm 24.25$ & $12.50 \pm 29.50$ & 0.45 & 1.00 & 0.18 \\
\hline & Control & $11.11 \pm 19.25$ & $9.09 \pm 15.57$ & $15.38 \pm 25.88$ & 1.00 & 0.41 & 0.46 \\
\hline \multirow[t]{2}{*}{ Financial problems (Q:28) } & Intervention & $19.54 \pm 31.52$ & $6.25 \pm 18.13$ & $8.89 \pm 19.79$ & 0.05 & 0.32 & 0.56 \\
\hline & Control & $34.92 \pm 41.47$ & $24.24 \pm 33.63$ & $25.64 \pm 33.76$ & 0.04 & 0.71 & 0.03 \\
\hline
\end{tabular}

second follow-up assessment (6 months). In total 14 patients in the intervention group and 7 patients in the control group discontinued their participation in the study due to personal or medical reasons. No adverse events were observed. On average patients in the intervention group attended $67 \%$ of the training sessions.

Quality of life. Quality of life (EORTC QLQ-C30) analysis of original data showed significant improvements in quality of life $(p=0.01)$, emotional functioning $(p<0.01)$, social functioning $(p=0.05)$, fatigue $(p=0.01)$ and pain $(p<0.01)$ from baseline to 6 months all in favor of the intervention group. Furthermore, significant improvements could be observed in social functioning $(p=0.03)$ and financial problems $(p=0.03)$ from baseline to 6 months in favor of the control group (Table II). Results of the breast cancer-specific EORTC QLQ-BR23 questionnaire showed a significant difference in breast symptoms $(p=0.01)$ and arm symptoms $(p=0.01)$ from baseline to 6 months in favor of the intervention group (Table III).

Level of physical activity. The analysis of the original data showed significant improvements in vigorous recreational activity ( $p=0.03$ ) from baseline to 6 months in favor of the intervention group. However, we observed a significant reduction in sedentary behavior $(p=0.03)$ from baseline to 3 months in favor of the control group (Table IV).

\section{Discussion}

When designing this randomized controlled two-armed intervention study we hypothesized that a holistic training program which is based on "Kyusho Jitsu" martial arts and lasts for 24 weeks is feasible and will have a positive effect 
in vivo $32: 819-824(2018)$

Table III. Original Data from the EORTC BR 23 (mean \pm s.d.) in the intervention and the control group and the results of the INTRA group comparison (Wilcoxon-test).

\begin{tabular}{|c|c|c|c|c|c|c|c|}
\hline EORTC-BR-23 parameters & Group & Baseline & 3 months & 6 months & $\begin{array}{c}p \text {-Value } \\
\text { (intragroup) } \\
\text { from baseline } \\
\text { to } 3 \text { months }\end{array}$ & $\begin{array}{c}p \text {-Value } \\
\text { (intragroup) } \\
\text { from } 3 \text { months } \\
\text { to } 6 \text { months }\end{array}$ & $\begin{array}{c}p \text {-Value } \\
\text { (intragroup) } \\
\text { from baseline } \\
\text { to } 6 \text { months }\end{array}$ \\
\hline \multirow[t]{2}{*}{ Body image (Q:9-12) } & Intervention & $60.63 \pm 27.27$ & $63.02 \pm 24.90$ & $71.35 \pm 27.72$ & 0.23 & 0.04 & 0.16 \\
\hline & Control & $61.11 \pm 31.22$ & $69.17 \pm 23.59$ & $76.39 \pm 25.58$ & 0.02 & 0.39 & 0.01 \\
\hline \multirow[t]{2}{*}{ Sexual functioning (Q:14.15) } & Intervention & $66.67 \pm 27.59$ & $65.63 \pm 23.94$ & $71.11 \pm 27.79$ & 1.00 & 0.12 & 0.32 \\
\hline & Control & $60.83 \pm 30.72$ & $68.18 \pm 27.34$ & $65.38 \pm 26.75$ & 0.17 & 0.79 & 0.25 \\
\hline \multirow[t]{2}{*}{ Sexual enjoyment (Q:16) } & Intervention & $29.17 \pm 16.67$ & $33.33 \pm 27.22$ & $33.33 \pm 37.27$ & 0.71 & 0.48 & 0.65 \\
\hline & Control & $28.89 \pm 24.77$ & $22.22 \pm 17.21$ & $33.33 \pm 35.63$ & 0.32 & 1.00 & 0.65 \\
\hline \multirow[t]{2}{*}{ Future perspective (Q:13) } & Intervention & $47.13 \pm 32.75$ & $50.00 \pm 29.81$ & $60.42 \pm 32.70$ & 1.00 & 0.18 & 0.25 \\
\hline & Control & $41.27 \pm 27.70$ & $45.45 \pm 30.81$ & $46.15 \pm 28.99$ & 0.21 & 0.65 & 0.16 \\
\hline \multirow{2}{*}{$\begin{array}{l}\text { Systematic therapy side-effects } \\
\text { (Q: } 1-4.6 .7 .8)\end{array}$} & Intervention & $30.71 \pm 13.02$ & $27.84 \pm 11.14$ & $28.57 \pm 9.86$ & 0.20 & 0.67 & 0.30 \\
\hline & Control & $37.34 \pm 23.98$ & $32.86 \pm 17.31$ & $32.94 \pm 18.66$ & 0.18 & 0.67 & 0.48 \\
\hline \multirow[t]{2}{*}{ Breast symptoms (Q:20-23) } & Intervention & $30.75 \pm 23.16$ & $25.00 \pm 16.67$ & $20.31 \pm 16.66$ & 0.04 & 0.16 & 0.01 \\
\hline & Control & $24.58 \pm 20.67$ & $21.97 \pm 18.36$ & $25.64 \pm 20.26$ & 0.72 & 0.55 & 0.89 \\
\hline \multirow[t]{2}{*}{ Arm symptoms (Q:17.18.19) } & Intervention & $38.89 \pm 29.08$ & $28.47 \pm 24.67$ & $23.61 \pm 25.94$ & 0.10 & 0.39 & 0.01 \\
\hline & Control & $33.86 \pm 27.32$ & $33.33 \pm 25.34$ & $34.19 \pm 24.62$ & 0.64 & 0.77 & 0.57 \\
\hline \multirow[t]{2}{*}{ Hair loss (Q:5) } & Intervention & $52.63 \pm 33.91$ & $58.33 \pm 34.50$ & $30.00 \pm 29.19$ & 0.26 & 0.05 & 0.27 \\
\hline & Control & $40.00 \pm 40.98$ & $41.67 \pm 50.00$ & $50.00 \pm 43.03$ & 0.32 & 1.00 & 0.32 \\
\hline
\end{tabular}

Table IV. Original Data from the QPAQ (mean \pm s.d.) in the intervention and the control group and the results of the INTRA group comparison (Wilcoxon-test).

\begin{tabular}{|c|c|c|c|c|c|c|c|}
\hline GPAQ-parameters & Group & Baseline & 3 months & 6 months & $\begin{array}{c}p \text {-Value } \\
\text { (intragroup) } \\
\text { from baseline } \\
\text { to } 3 \text { months }\end{array}$ & $\begin{array}{l}p \text {-Value } \\
\text { (intragroup) } \\
\text { from } 3 \text { months } \\
\text { to } 6 \text { months }\end{array}$ & $\begin{array}{c}p \text {-Value } \\
\text { (intragroup) } \\
\text { from baseline } \\
\text { to } 6 \text { months }\end{array}$ \\
\hline Total Physical Activity & Intervention & $4766.37 \pm 4527.56$ & $5406.67 \pm 4100.85$ & $6458.75 \pm 5407.88$ & 0.14 & 0.35 & 0.09 \\
\hline MET-minutes/week & Control & $5081.90 \pm 4606.44$ & $6324.44 \pm 4867.30$ & $4675.71 \pm 4836.74$ & 0.64 & 0.31 & 0.97 \\
\hline MET value of vigorous & Intervention & $1166.90 \pm 3073.31$ & $53.33 \pm 206.56$ & $405.00 \pm 1496.80$ & 0.14 & 0.65 & 0.25 \\
\hline work activity per week & Control & $342.86 \pm 1571.17$ & $2240.00 \pm 3779.52$ & $960.00 \pm 3082.14$ & 0.11 & 0.59 & 0.65 \\
\hline MET value of moderate & Intervention & $1065.00 \pm 1661.46$ & $1587.50 \pm 2516.62$ & $2032.50 \pm 2466.08$ & 0.54 & 0.29 & 0.24 \\
\hline work activity per week & Control & $1365.71 \pm 1868.14$ & $960.00 \pm 1428.96$ & $857.14 \pm 1508.27$ & 0.75 & 0.07 & 0.44 \\
\hline MET value of transport & Intervention & $950.76 \pm 1102.39$ & $1743.75 \pm 1622.92$ & $1453.75 \pm 1634.28$ & 0.65 & 0.42 & 1.00 \\
\hline activity per week & Control & $1519.05 \pm 1970.91$ & $901.82 \pm 1040.98$ & $900.00 \pm 885.92$ & 0.23 & 0.68 & 0.35 \\
\hline MET value of vigorous & Intervention & $638.57 \pm 643.37$ & $1302.50 \pm 2396.89$ & $1432.50 \pm 1080.86$ & 0.88 & 0.43 & 0.03 \\
\hline recreational activity per week & Control & $1388.57 \pm 1644.34$ & $981.82 \pm 1009.45$ & $1397.14 \pm 2496.64$ & 0.63 & 0.94 & 0.59 \\
\hline MET value of moderate & Intervention & $782.76 \pm 774.89$ & $1367.50 \pm 1323.06$ & $1135.00 \pm 841.86$ & 0.01 & 0.67 & 0.06 \\
\hline recreational activity per week & Control & $465.71 \pm 418.15$ & $649.09 \pm 475.43$ & $561.43 \pm 658.79$ & 0.72 & 0.77 & 0.88 \\
\hline Minutes spent in sedentary & Intervention & $310.34 \pm 171.27$ & $320.63 \pm 161.26$ & $29.38 \pm 170.14$ & 0.38 & 0.53 & 0.84 \\
\hline activities on average per day & Control & $393.00 \pm 144.66$ & $318.18 \pm 195.90$ & $325.71 \pm 222.60$ & 0.03 & 0.30 & 0.13 \\
\hline
\end{tabular}

on physical activity levels and health-related quality of life in breast cancer survivors. To our knowledge this is the first study showing that a targeted Kyusho Jitsu martial arts intervention is safe, feasible and can be effective for breast cancer survivors. However, this may only be applicable for women who are willing to commit their time and can identify with the intervention. A significant effect was detected in favor of the intervention over six months, that support the findings of Sprod and colleagues who suggest that martial arts, in their case tai chi chuan, may improve health-related quality of life (21). Irwin and colleagues suggest that tai chi can counteract treatment-related side effects, such as insomnia (22). The findings of Larkey and colleagues, that martial arts interventions may decrease fatigue, the most commonly 
experienced side effect, were also supported $(16,23)$. Further, it may lead to improvements in overall quality of life (24) and psychological well-being (14). The current literature suggests that breast cancer patients reduce their physical activity levels during medical treatment and they often remain low thereafter (25), which increases the risk of cardiovascular diseases and impaired QoL (26). A significant improvement in physical activity level was observed in our study, suggesting that a martial arts intervention has the capability to motivate breast cancer patients to change their physical activity behavior. Hence the overall time being active per week was not only increased through the intervention itself, but also through the recreational time spent active. The perceived improvements in quality of life and fatigue may have encouraged patients to exercise outside of the supervised training program to further improve their wellbeing. During recreation, individuals tend to select activities that they enjoy doing. This individual training has been found to have a more sustainable impact on physical activity levels in breast cancer patients (27).

The strength of this study is that it is the first randomized, controlled, supervised Kyusho Jitsu-based martial arts study in breast cancer survivors. The groups were comparable at baseline with regard to all clinical data, however the control group was significantly younger. In addition, we observed a significant difference at baseline between both groups in physical functioning and fatigue which could have modified the observed improvement in the intervention group. The high drop-out rate of $42 \%$ is certainly a limitation of this study because the time commitment was not feasible for nine out of 21 drop-outs. Since no adverse events occurred, we propose that the intervention is feasible despite the drop-out rate. This study was intentionally designed as a cross-over study, however due to the high drop-out rate before and after the cross-over, the study was discontinued. Previous martial arts studies have also reported relatively high drop-out rates, suggesting that these type of interventions are not suitable for everyone $(17,16)$. This applies to our study as well. The high drop-out rate may also be due to the fact that Kyusho Jitsu is a very unique sort of martial arts and not everyone can identify with the training regime. On the other hand, eleven patients joined a Kyusho Jitsu club after the study. A further limitation of this study is the small sample size, which increases the source of error (small variations and early drop outs had a huge impact on the scores). In addition, the exercise intervention was hard to standardize because the training tailored to each individual.

To summarize, our prospective, randomized-controlled two-armed intervention study suggests that a targeted martial arts intervention can support the well-being of breast cancer survivors by improving quality of life and emotional functioning and reducing fatigue. It can also enhance physical recovery by improving and stabilizing physical activity levels in breast cancer patients.

\section{Conflicts of Interest}

The Authors declare that they have no competing interests.

\section{Acknowledgements}

The study was funded by an anonymous contributor.

\section{References}

1 McGuire A, Brown J, Malone C, McLaughlin R and Kerin M: Effects of Age on the Detection and Management of Breast Cancer. Cancers 7: 908-929, 2015.

2 Parkin DM, Bray F, Ferlay $\mathrm{J}$ and Pisani P: Global cancer statistics, 2002. CA Cancer J Clin 55: 74-108, 2005.

3 Howlader N, Noone AM, Krapcho M, Miller D, Bishop K, Altekruse SF, Kosary CL, Yu M, Ruhl J, Tatalovich Z, Mariotto A, Lewis DR, Chen HS, Feuer EJ and Cronin KA: SEER Cancer Statistics Review, 1975-2013. based on November 2015 SEER data submission, posted to the SEER web site. http:// seer.cancer.gov/csr/1975_2013, April 2016.

4 Burstein HJ: Side effects of chemotherapy. Case 1. Radiation recall dermatitis from gemcitabine. J Clin Oncol 18(3): 693-694, 2000.

5 Burish TG and Tope DM: Psychological techniques for controlling the adverse side effects of cancer chemotherapy: findings from a decade of research. J Pain Symptom Manage 7: 287-301, 1992.

6 Levangie PK, Santasier AM, Stout NL and Pfalzer L: A qualitative assessment of upper quarter dysfunction reported by physical therapists treated for breast cancer or treating breast cancer sequelae. Support Care Cancer 19: 1367-1378, 2011.

7 Mulders M, Vingerhoets A and Breed W: The impact of cancer and chemotherapy: perceptual similarities and differences between cancer patients, nurses and physicians. Eur J Oncol Nurs 12: 97-102, 2008.

8 Rosedale M and Fu MR: Confronting the unexpected: temporal, situational, and attributive dimensions of distressing symptom experience for breast cancer survivors. Oncol Nurs Forum 37: E28-33, 2010.

9 Tofthagen C: Patient perceptions associated with chemotherapyinduced peripheral neuropathy. Clin J Oncol Nurs 14: E22-28, 2010.

10 Shakeri J, Golshani S, Jalilian E, Farnia V, Nooripour R, Alikhani M and Yaghoobi K: Studying the amount of depression and its role in predicting the quality of life of women with breast cancer. Asian Pac J Cancer Prev 17: 643-646, 2016.

11 Ridner SH: Quality of life and a symptom cluster associated with breast cancer treatment-related lymphedema. Support Care Cancer 13: 904-911, 2005.

12 Velthuis MJ, Agasi-Idenburg SC, Aufdemkampe G and Wittink HM: The effect of physical exercise on cancer-related fatigue during cancer treatment: a meta-analysis of randomised controlled trials. Clin Oncol (R Coll Radiol) 22: 208-221, 2010.

13 Robert JT, Mea Holm and Ali Al-Adhami: Physical activity after cancer: An evidence review of the international literature. Brit J Med Pract 7: a708, 2014.

14 Abbott R and Lavretsky H: Tai Chi and Qigong for the treatment and prevention of mental disorders. Psychiatr Clin North Am 36: 109-119, 2013. 
15 Campo RA, O'Connor K, Light KC, Nakamura Y, Lipschitz DL, LaStayo PC, Pappas L, Boucher K, Irwin MR, Agarwal N and Kinney AY: Feasibility and acceptability of a Tai Chi Chih randomized controlled trial in senior female cancer survivors. Integr Cancer Ther 12: 464-474, 2013.

16 Larkey LK, Roe DJ, Weihs KL, Jahnke R, Lopez AM, Rogers $\mathrm{CE}, \mathrm{Oh} \mathrm{B}$ and Guillen-Rodriguez J: Randomized controlled trial of Qigong/Tai Chi easy on cancer-related fatigue in breast cancer survivors. Ann Behav Med 49: 165-176, 2015.

17 Janelsins MC, Davis PG, Wideman L, Katula JA, Sprod LK, Peppone LJ, Palesh OG, Heckler CE, Williams JP, Morrow GR and Mustian KM: Effects of Tai Chi Chuan on insulin and cytokine levels in a randomized controlled pilot study on breast cancer survivors. Clin Breast Cancer 11: 161-170, 2011.

18 WMA Declaration of Helsinki - Ethical Principles for Medical Research Involving Human Subjects. Available from: https:// www.wma.net/wp-content/uploads/2016/11/DoH-Oct2013JAMA.pdf [last accessed 2 April 2018]

19 Fayers PM, Aaronson NK, Bjordal K, Groenvold M, Curran D and Bottomley A: EORTC QLQ-C30 Scoring Manual (3rd edition). On behalf of the EORTC Quality of Life Group. Brussels, EORTC, 2001. Available from: http://www.eortc.be/ qol/files/SCManualQLQ-C30.pdf [last accessed 2 April 2018]

20 Armstrong $\mathrm{T}$ and Bull F: Development of the World Health Organization Global Physical Activity Questionnaire (GPAQ). J Public Health 14: 66-70, 2006.

21 Sprod LK, Janelsins MC, Palesh OG, Carroll JK, Heckler CE, Peppone LJ, Mohile SG, Morrow GR and Mustian KM: Healthrelated quality of life and biomarkers in breast cancer survivors participating in tai chi chuan. J Cancer Surviv 6: 146-154, 2012.

22 Irwin MR, Olmstead R, Carrillo C, Sadeghi N, Nicassio P, Ganz PA and Bower JE: Tai Chi Chih compared with cognitive behavioral therapy for the treatment of insomnia in survivors of breast cancer: A randomized, partially blinded, noninferiority trial. J Clin Oncol 35: 2656-2665, 2017.
23 Prue G, Rankin J, Allen J, Gracey J and Cramp F: Cancer-related fatigue: A critical appraisal. Eur J Cancer 42: 846-863, 2006.

24 Galantino ML, Callens ML, Cardena GJ, Piela NL and Mao JJ: Tai chi for well-being of breast cancer survivors with aromatase inhibitor-associated arthralgias: a feasibility study. Altern Ther Health Med 19: 38-44, 2013.

25 Vardar-Yagli N, Sener G, Saglam M, Calik-Kutukcu E, Arikan H, Inal-Ince D, Savci S, Altundag K, Kutluk T, Ozisik Y and Kaya EB: Associations among physical activity, comorbidity, functional capacity, peripheral muscle strength and depression in breast cancer survivors. Asian Pac J Cancer Prev 16: 585-589, 2015.

26 Elme A, Utriainen M, Kellokumpu-Lehtinen P, Palva T, Luoto $R$, Nikander $R$, Huovinen $R$, Kautiainen $H$, Järvenpää $S$, Penttinen HM, Vehmanen L, Jääskeläinen A-S, Ruohola J, Blomqvist $\mathrm{C}$ and Saarto T: Obesity and physical inactivity are related to impaired physical health of breast cancer survivors. Anticancer Res 33: 1595-1602, 2013.

27 Baumann FT, Bieck O, Oberste M, Kuhn R, Schmitt J, Wentrock S, Zopf E, Bloch W, Schule K and Reuss-Borst M: Sustainable impact of an individualized exercise program on physical activity level and fatigue syndrome on breast cancer patients in two German rehabilitation centers. Support Care Cancer 25: 1047-1054, 2017. 